\title{
Vaccines against infectious coryza
}

\author{
P.J. BLACKALL \\ Queensland Department of Primary Industries, Animal Research \\ Institute, 665 Fairfield Road, Yeerongpilly 4105, Australia
}

The paper reviews the literature on vaccines against infectious coryza of chickens. Our knowledge of natural immunity, antigens involved in protection and the degree of cross-serovar protection provided by vaccines is summarized. The effect of variables such as antigen dose, inactivating agent and adjuvant type on vaccine efficacy is reviewed. The protective ability of a new generation infectious coryza vaccine based on a live attenuated strain of Haemophilus paragallinarum is discussed.

Keywords: Infectious coryza; vaccine; Haemophilus paragallinarum.

\section{Introduction}

Infectious coryza, an upper respiratory tract infection of chickens caused by the bacterium Haemophilus paragallinarum, may occur in both growing chickens and layers. The major economic effect of the disease is an increased culling rate in meat chickens and a reduction in egg production (10-40\%) in laying and breeding fowl, particularly on multi-age farms (Yamamoto, 1991).

This paper reviews the literature on laboratory based evaluations of vaccines against infectious coryza. These studies have, in general, been performed using a challenge system based on either intrasinus or intranasal inoculation of $H$. paragallinarum. The paper does not attempt to provide a complete review of either the disease or the causative agent. Other reviews are available that cover these areas (Blackall, 1989; Blackall and Yamamoto, 1990; Yamamoto, 1991).

\section{The organism}

The causative agent of infectious coryza, $H$. paragallinarum, is recognized as a Gram-negative organism that has an in vitro growth requirement for nicotinamide adenine dinucleotide (NAD; $V$ factor). Recently, it has been recognized that some strains of $H$. paragallinarum isolated from poultry in South Africa are apparently V factor independent (Horner et al., 1992; Mouahid et al., 1992; Bragg et al., 1993). These strains have been shown to be typical $H$. paragallinarum in all other properties other than the fact that they do not require $\mathrm{V}$ factor in a complex medium (Horner et al., 1992; Mouahid et al., 1992). 
The most widely used serotyping scheme for $H$. paragallinarum is that described by Page (1962) which recognizes three serovars (A, B and C). Some reports have cast doubt on the validity of Page's serovar B, suggesting that the members of this serovar are really only variants of serovars A or C (Sawata et al., 1980). However, it has recently been conclusively demonstrated that Page serovar B is a true serovar and that, with the exception of reference strain 0222 , isolates of serovar B are fully pathogenic (Yamaguchi et al., 1990).

The Kume serotyping scheme is an alternative to the Page scheme (Kume et al., 1983). This recognizes three serogroups which have recently been shown to correspond to Page serovars A, B and C (Blackall et al., 1990). Further minor differences exist and can be detected by the use of absorbed antisera, resulting in a typing scheme that, when initially proposed, recognized three serogroups and seven serovars. New serovars have recently been added to the Kume scheme and a new terminology has been adopted in which three serogroups (A, B and C) are recognized, with the serovars within the serogroups being identified numerically. Currently the recognized Kume serovars are A-1, A-2, A-3, A-4, B-1, C-1, C-2, C-3 and C-4 (Blackall et al., 1990). The new terminology emphasizes that the Page serovars and the Kume serogroups are equivalent.

\section{Natural immunity}

Chickens that recover from a natural infection of infectious coryza possess varying degrees of immunity. It has been shown that homologous immunity develops as early as two weeks after the initial exposure (Sato and Shifrine, 1964). Rimler et al. (1977) have shown that infection results in homologous immunity as well as some degree of heterologous immunity that extends across the Page serovars.

\section{Protective antigens}

The protective antigens of $H$. paragallinarum have not been convincingly identified. Sawata et al. (1979) suggested that the capsule of $H$. paragallinarum contains protective antigens. A crude polysaccharide has also been reported to provide protection that is limited to the Page serovar on which the vaccine is based (Iritani et al., 1981).

Other studies have suggested that the haemagglutinin (HA) antigens may be protective antigens. Iritani et al. (1980) have shown that a purified haemagglutinin preparation from an agglutinin serovar A strain gave homologous protection. Several studies have noted a correlation between haemagglutination-inhibition (HI) titres and subsequent immunity to challenge. The most convincing evidence of the role of HA antigens in protection has only recently emerged. Takagi et al. (1991) have shown that chickens treated with monoclonal antibodies against the HA antigen of $H$. paragallinarum serovar A showed no clinical signs on challenge. The monoclonal antibodies also reduced the amount of the challenge organism present in the sinuses of the treated chickens compared with untreated controls (Takagi et al., 1991).

There is considerable evidence that the protective antigens of $H$. paragallinarum are surface located. The antigens so far implicated have been the agglutinin antigens detected during Page serotyping, HA antigens and some component or components of the polysaccharide content of the cell. However, there still remains considerable confusion. It seems probable that there is not just one protective 
antigen. A number of different antigens (outer membrane proteins, polysaccharides, lipopolysaccharides) are all likely to be involved.

\section{Cross-protection}

As mentioned above, there is evidence that natural infection results in subsequent immunity which offers both homologous and heterologous protection across the Page serovars (Sato and Shifrine, 1964; Rimler and Davis, 1977). In considering the literature on the degree of cross-serovar protection conferred by killed whole cell vaccines, there are two issues that can confuse the interpretation of research results. Firstly, different studies have defined 'protection' in differing ways. Some workers have evaluated protection only in terms of the presence or absence of clinical signs. Other workers have defined protection as meaning the absence of clinical signs, absence of mucus in the sinuses and absence of the challenge organism from the sinuses. Clearly, the last definition is far more demanding than the simple absence of clinical signs.

The other issue that must be considered when examining cross-serovar protection relates to the serotyping scheme used. Most studies of cross-protection have involved isolates which have been serotyped by the Page scheme, i.e. into serovars A, B or C (Page, 1962). The recently developed Kume scheme (Kume et al., 1983) allows a finer serotyping of $H$. paragallinarum. Hence, it is possible for isolates of $H$. paragallinarum to belong to the same Page serovar but different Kume serovars. For example, isolates HP31 and HP60 are both Page serovar C (i.e. Kume serogroup C) but Kume serovars C-2 and C-4, respectively (Blackall et al., 1990).

Bearing the above constraints in mind, there is a general agreement in the literature about the cross-protection afforded by killed infectious coryza vaccines. Workers who have used vaccines based on egg yolk cultures or on tissue culture grown antigens have reported some degree of cross-protection between the Page serovars (Page et al., 1963; Wichmann and Wichmann, 1983). In contrast, killed vaccines based on broth grown antigen have been shown to provide little protection across the Page serovars (Rimler et al., 1977; Kume et al., 1980b; Blackall and Reid, 1987). The explanation for the difference between egg-based and brothbased vaccines in terms of their cross-protection appears to be related to their antigenic make-up. As natural infection results in cross-serovar protection, it seems likely the egg-produced antigen must resemble more closely the natural antigenic make-up of the organism in the chicken than does the broth grown antigen. The fact that egg-based vaccines provide some degree of cross-serovar protection should not be taken as a broad recommendation for this type of vaccine. Several studies have demonstrated that broth-based vaccines are more effective than egg-based vaccines in terms of homologous protection (Matsumoto and Yamamoto, 1975; Davis et al., 1976).

Evaluating the literature about the relevance of cross-protection between the Kume serovars is more difficult as the Kume scheme has not yet been widely used. However, the overall evidence is that the Kume serogroups are not cross-protective. Within a Kume serogroup it appears that there is significant cross-protection between the serovars. Specific evidence to date is that, firstly, Kume serovars $\mathrm{C}-1$ and $\mathrm{C}-2$ and $\mathrm{C}-2$ and $\mathrm{C}-4$ are cross-protective; and, secondly, Kume serovars A-1 and C-1, A-1 and C-2, A-4 and C-2 and A-4 and C-4 are not cross-protective (Kume et al., 1980b; Blackall and Reid, 1987; Blackall, 1991). 
Special mention needs to made of Page serovar B. Yamaguchi et al. (1991) have shown that different strains of serovar B provided only partial cross-protection amongst themselves. The confirmed existence of Page serovar B as a true serovar with full pathogenicity and its widespread existence - e.g. in Argentina and Brazil (Terzolo et al., 1993; Blackall et al., 1994b) - means that this serovar must be included in inactivated vaccines if the target poultry population is at risk from a serovar B challenge. The recognition of serovar B as a necessary component of infectious coryza vaccines is evidenced by the fact that commercial inactivated vaccines containing virulent serovar B strains are now available (Jacobs et al., 1992).

\section{Growth media for vaccine production}

Different antigen preparation methods for infectious coryza vaccines have been reported including propagation in the yolk sac of chicken embryos, broth cultures and cell culture. Egg propagation was the method used in the early 1960 s for the production of the earliest infectious coryza vaccines (Page et al., 1963). While these early vaccines did not give good protection against the clinical signs of infectious coryza, they did prevent the development of secondary air sac lesions and reduced the fall in egg production associated with outbreaks of infectious coryza. Subsequent work has shown that broth-based vaccines give better protection than egg-propagated products (Matsumoto and Yamamoto, 1975; Davis et al., 1976). There is one report of the production of infectious coryza vaccines in avian tissue cultures (Wichmann and Wichmann, 1983). This single study reported that this tissue culture-based vaccine was superior to vaccines produced in conventional broths (Wichmann and Wichmann, 1983). As most recent literature has involved the use of broths to produce infectious coryza vaccines, the remainder of this paper will be concerned with the efficacy of these broth-produced vaccines.

A range of different broth media have been used for production of infectious coryza vaccines. Media that have been shown to result in effective vaccines include chicken meat infusions of various types (Matsumoto and Yamamoto, 1971; Kume et al., 1980c) and a modified Casman broth (Rimler et al., 1975; Blackall and Reid, 1987). There appear to have been no direct comparisons of vaccines produced in different media so the relative efficacy of the media cannot be directly compared.

\section{Antigen levels}

The sole published study to date on the influence of antigen level established that $10^{8}$ colony forming units per vaccine dose is the minimum needed to give good protection (Matsumoto and Yamamoto, 1975).

\section{Inactivating agents}

There is disagreement in the literature on the effect of different inactivating agents. Several studies have confirmed that thiomersal is effective (Matsumoto and Yamamoto, 1975; Davis et al., 1976; Blackall and Reid, 1987). Others have reported that vaccines in which formalin was used as the inactivating agent were also effective (Rimler et al., 1975; Coetzee et al., 1982).

There have been three direct comparisons of vaccines for which the antigen and adjuvant phases were exactly the same and only the inactivating agent 
differed. In all three of these comparisons formalin reduced the efficacy of the vaccines although there was evidence that the effect was adjuvant specific. In one of these direct comparisons the use of formalin, compared with thiomersal, resulted in a reduction in the efficacy of aluminium hydroxide-based vaccines (Blackall and Reid, 1987). The second study (Matsumoto and Yamamoto, 1971) found that formalin, compared with thiomersal, impaired the efficacy of a vaccine containing chrome alum as an adjuvant. However, these authors found no difference between thiomersal and formalin for vaccines containing aluminium hydroxide gel. In the remaining study formalin reduced the efficacy of vaccines containing either mineral oil or aluminium hydroxide gel compared with the use of thiomersal (Davis et al., 1976). Overall, the evidence is that, while vaccines containing formalin as the inactivating agent can be protective, it is possible that a similar vaccine containing thiomersal would be even more efficient.

\section{Adjuvants}

The following sections review the literature on the different adjuvant systems that have been evaluated for inactivated infectious coryza vaccines. Again, it is important to realize that different criteria for protection have been used. Some of the conflicting results recorded in the literature may therefore arise from the use of different definitions of 'protection'. The various candidate vaccines will be reviewed from the view of both efficacy and safety (minimal adverse reactions to vaccination).

The aspect of adverse reactions is an important consideration with infectious coryza vaccines. It has been suggested that adverse reactions are associated with either the adjuvant used or the lipopolysaccharide (LPS) present in the $H$. paragallinarum cells (Iritani et al., 1981). The LPS of $H$. paragallinarum has been shown to be lethal for embryonated chicken eggs and to be positive in a pyrogen test (Konno and Nakase, 1977). Iritani et al. (1981) have also shown that a crudely purified polysaccharide extract contains a component that is toxic and causes hydropericardium following intravenous inoculation into chickens. Any records of adverse side reactions will be noted with the various adjuvant systems described below.

\section{Aluminium hydroxide gel}

A number of studies have confirmed that aluminium hydroxide gel is an effective adjuvant system (Matsumoto and Yamamoto, 1971; Davis et al., 1976; Kume et al., 1980c; Reid and Blackall, 1987). Chrome alum has also been found to be an effective adjuvant (Matsumoto and Yamamoto, 1971). Blackall and Reid (1987) found that the use of two commercial brands of aluminium hydroxide gel resulted in equally effective vaccines. All the studies that have evaluated aluminium hydroxide gel vaccines for adverse reactions have reported either no such reactions or only minor reactions at the vaccination site (Matsumoto and Yamamoto, 1971; Boycott et al., 1977; Blackall and Reid, 1987; Reid and Blackall, 1987; Blackall et al., 1992).

\section{Mineral oil (single emulsion type)}

Those vaccines that contain mineral oil in a single emulsion system, i.e. a water-in-oil emulsion type, are described. The alternative system - a double 
emulsion - is reviewed below. Clark and Godfrey (1961) found that eggpropagated mineral oil-containing vaccines did confer some degree of protection compared with unvaccinated controls. The vaccinated chickens developed clinical signs although their severity was less than among the unvaccinated controls. In addition, the recovery of the vaccinated chickens was quicker and the incidence of complications was lower than for the unvaccinated controls (Clark and Godfrey, 1961). It is possible that the relatively low efficacy of this particular vaccine could have been due to factors other than the adjuvant system, e.g. the use of egg-propagated antigen or formalin as the inactivating agent. A later study by Matsumoto and Yamamoto (1971) of a commercial egg-propagated mineral oil-based vaccine showed similar low efficacy.

In the case of broth propagation, there is still disagreement over the efficacy of mineral oil-based vaccines. In one study involving a direct comparison of vaccines based on the same antigen and different adjuvant systems, mineral oil-based vaccines conferred some protection, but much less than that given by a vaccine containing aluminium hydroxide gel as a vaccine (Reid and Blackall, 1987). These authors evaluated two different concentrations of oil in the adjuvant component, but no improvement in the efficacy of the products resulted. In contrast, the direct comparison performed by Davis et al. (1976) resulted in no great difference between mineral oil- and aluminium hydroxidebased vaccines. A study from South Africa has reported that mineral oil-based vaccines outperformed an aluminium hydroxide-containing vaccine (Coetzee et al., 1982). However, the results of this study must be treated with caution. The mineral oil-based vaccines contained a Page serovar $A$ and $B$ strain while the aluminium hydroxide gel vaccine contained a Page serovar $A$ and $C$. As the challenge used was a mixture of Page serovar $A$ and $B$, the aluminium hydroxide-based vaccine did not contain the appropriate serovars to match the challenge strains used. Jacobs et al. (1992) have recently reported that a vaccine that includes all three Page serovars and is based on a mineral oil emulsion gave good protection.

The conflicting results over the efficacy of mineral oil-based vaccines are probably due to formulation issues. It would appear that, provided the adjuvant phase is formulated correctly, it is possible to produce mineral oil-based infectious coryza vaccines that are efficacious.

Another important aspect of mineral oil-based vaccines is the safety of the product. Mineral oil-based vaccines caused localized swellings in 15 of 20 vaccinated birds and granulomas in 18 of 20 birds in one study (Reid and Blackall, 1987). The authors considered the severity of these reactions to be unacceptable for commercial poultry operations. Other studies that have examined the use of mineral oil-based infectious coryza vaccines have not indicated whether any specific examinations for adverse reactions associated with vaccination were performed. This failure to record whether adverse reactions occurred or not is a major deficiency, given the knowledge that $H$. paragallinarum LPS has been shown to be pyrogenic (Konno and Nakase, 1977). Candidate infectious coryza vaccines that contain mineral oil should be carefully screened for evidence of adverse side reactions.

In an attempt to improve the efficacy of mineral oil-based vaccines, those that contain both aluminium hydroxide and mineral oil have been evaluated. While such vaccines were very effective, they gave even more severe adverse reactions than the mineral oil-based products (Reid and Blackall, 1987). 


\section{Mineral oil (double emulsion type)}

A double emulsion adjuvant represents an alternative method of combining the antigen phase and the adjuvant phase. It is created by re-emulsifying a simple water-in-oil emulsion in an outer water phase. In the initial evaluation (Blackall, 1988 ) this type of vaccine was found to give a very poor level of protection. However, no evidence of adverse reactions to the vaccine was found. The oil used in the double emulsion type vaccines was the same batch as that used in simple water-in-oil vaccines which caused quite severe adverse reactions (Reid and Blackall, 1987). Yet, these adverse reactions were absent when the same oil was used in a double emulsion system. This suggests that the method of formulation of a double emulsion vaccine has some modulating effect upon the toxicity of mineral oil-based vaccines containing inactivated cells of $H$. paragallinarum.

Recent work with double emulsion systems has given far more encouraging results. Double emulsion vaccines produced by an Australian manufacturer, experienced in the production of this type of vaccine, have been very effective and have given high levels of protection (Blackall et al., 1992). They have also caused very few adverse reactions at the site of inoculation (breast muscle). These results indicate that the double emulsion system, provided it is formulated correctly, represents both a safe and effective adjuvant system for infectious coryza vaccines.

\section{Alternative adjuvant systems}

There appear to have been only two studies of the suitability of adjuvants other than aluminium hydroxide and mineral oil for infectious coryza vaccines (Reid and Blackall, 1987; Blackall, 1988). Vaccines based on Quil A, a saponin, were found to have very little efficacy (Reid and Blackall, 1987). It is possible that a combined aluminium hydroxide gel-Quil A adjuvant may be more effective than either component alone. Such a combined adjuvant is worth evaluating.

Similarly, the lipoidal amine, avridine, did not appear to have any effective adjuvant role in inactivated infectious coryza vaccines (Blackall, 1988). Avridine is a potent stimulator of interferon and is regarded as an effective adjuvant for the stimulation of mucosal immunity (Jensen, 1986). However, no efficacy could be found whether avridine was used as a sole adjuvant or in combination with both aluminium hydroxide gel and a double emulsion type adjuvant, or if used by the intramuscular or the intranasal routes (Blackall, 1988). As the three methods used to incorporate avridine into the vaccines have been shown by others to be effective, it appears unlikely that formulation problems are the explanation of the poor performance of avridine. It would appear that the adjuvant activity of avridine is not relevant for infectious coryza vaccines.

\section{Routes of administration}

The bulk of the literature on inactivated infectious coryza vaccines indicates that in most studies either the intramuscular or the subcutaneous route has been used (Matsumoto and Yamamoto, 1975; Davis et al., 1976). The only direct comparison of the effect of administering one vaccine by different routes established that an aluminium hydroxide-based vaccine was effective when given either subcutaneously (into the back of the neck) or intramuscularly (into breast muscle) but totally ineffective when given intranasally (Blackall and Reid, 1987). It has been reported that better protection is induced if aluminium hydroxide-based vaccine is given into the leg muscle rather than the breast muscle (Iritani et al., 1984). 


\section{Duration of immunity}

The duration of the immunity induced by infectious coryza vaccines has been examined in a number of studies. Matsumoto and Yamamoto (1975) were able to demonstrate that a single dose of aluminium hydroxide-based vaccine gave significant protection up to nine months after vaccination. Kume et al. (1980a) were able to achieve significant protection for up to 30 weeks after vaccination, although this work was performed using two doses of the aluminium hydroxidebased vaccine. Blackall and Reid (1987) reported that aluminium hydroxide-based vaccines can give some degree of protection for up to 56 weeks after vaccination with a higher level of protection if two doses of the vaccine are given.

The overall view from the literature is that, in vaccine evaluations based on short time periods, a single dose of an aluminium hydroxide-based vaccine is as effective as a double dose. However, it appears likely that, for longer term protection, aluminium hydroxide vaccines should be given as two doses, at least three weeks apart.

\section{Live infectious coryza vaccine}

The cross-serovar protection associated with natural infections (Rimler and Davis, 1977) has been exploited by the use of 'controlled exposure' in which flocks are deliberately exposed to live $H$. paragallinarum before onset of lay (Yamamoto, 1991). However, the use of live virulent $H$. paragallinarum strains is clearly a dangerous practice which should only be performed under limited and controlled conditions. A live, non-pathogenic strain of $H$. paragallinarum should have the advantage of cross-serovar protection without the disadvantage of adverse reactions associated with the use of a virulent pathogen.

Blackall and colleagues have described their progress towards a live, attenuated infectious coryza vaccine. In the initial work they confirmed that infection with a fully virulent serovar $\mathrm{C}$ strain provides subsequent protection against a different serovar $\mathrm{C}$ strain as well as a serovar A strain (Blackall et al., 1993). Non-pathogenic mutated strains derived from a serovar $A$ or a serovar $C$ parent by chemical mutagenesis have been created (Blackall et al., 1993). A good level of protection against challenge from either a virulent serovar A or C strain following eyedrop vaccination with a non-pathogenic candidate vaccine strain has been demonstrated (Blackall et al., 1994a).

\section{Conclusions}

Research into effective infectious coryza vaccines has been in progress for over 30 years. In that time much has been learnt about the requirements for an effective infectious coryza vaccine. It has been repeatedly demonstrated that whole cell vaccines that have been inactivated with thiomersal and contain aluminium hydroxide gel as the adjuvant provide good protection, particularly against clinical signs, but may not prevent infection. This protection is limited to the Page serovar(s) included in the vaccine. Alternative adjuvant systems such as mineral oil double emulsions have been shown to be equally effective provided that they are correctly formulated. Current work on a live infectious coryza vaccine may result in an entirely new approach to vaccination.

While much has been gained over the past 30 years, definitive knowledge is still lacking in many areas. Recent development of monoclonal antibodies and the 
application of these reagents, together with molecular biological techniques, promises a new era in infectious coryza vaccine research. It is possible that, in the near future, the key antigens responsible for protection may be identified. Similarly it may be possible to identify all those antigens associated with adverse reactions and so produce vaccines that give high levels of protection across all three Page serovars, but which avoid toxic or adverse side reactions. One of the challenges of the future will be to keep this potential 'super' vaccine cost effective and hence relevant to the practical world of poultry farming.

\section{References}

BLACKALL, P.J. (1988) Further comparison of adjuvants for an inactivated infectious coryza vaccine. Avian Diseases 32: 831-835

BLACKALL, P.J. (1989) The avian haemophili. Clinical Microbiology Reviews 2: 270-277

BLACKALL, P.J. (1991) An evaluation of the cross protection afforded by inactivated infectious coryza vaccines. Australian Veterinary Journal 68: 266-267

BLACKALL, P.J. and REID, G.G. (1987) Further efficacy studies on inactivated, aluminum-hydroxideadsorbed vaccines against infectious coryza. Avian Diseases 31: 527-532

BLACKALL, P.J. and YAMAMOTO, R. (1990) Infectious coryza. In: A Laboratory Manual for the Isolation and Identification of Avian Pathogens (Eds Purchase, H.G., Arp, L.H., Domermuth, C.H. and Pearson, J.E.), American Association of Avian Pathologists, Ames, pp. 27-31

BLACKALL, P.J., EAVES, L.E. and ROGERS, D.G. (1990) Proposal of a new serovar and altered nomenclature for Haemophilus paragallinarum in the Kume hemagglutinin scheme. Journal of Clinical Microbiology 28: 1185-1187

BLACKALL, P.J., EAVES, L.E., ROGERS, D.G. and FIRTH, G. (1992) An evaluation of inactivated infectious coryza vaccines containing a double-emulsion adjuvant system. Avian Diseases 36 : $632-636$

BLACKALL, P.J., RAFIEE, M., GRAYDON, R.J. and TINWORTH, D. (1993) Towards a live infectious coryza vaccine. Proceedings of the XIIth World Veterinary Poultry Association Conference p. 99

BLACKALL, P.J., RAFIEE, M., GRAYDON, R.J. and TINWORTH, D. (1994a) Progress towards a live infectious coryza vaccine. Western Poultry Disease Conference 23: 151

BLACKALL, P.J., SILVA, E.N., YAMAGUCHI, T. and IRITANI, Y. (1994b) Characterization of isolates of avian hemophili from Brazil. Avian Diseases 38: 269-274

BOYCOTT, B.R., RIMLER, R.B. and DAVIS, R.B. (1977) Experimental coryza in broiler chicks. I. Effects of vaccination with Haemophilus gallinarum bacterin and its components on weight gains and resistance to infection. Avian Diseases 21: 364-369

BRAGG, R.R., COETZEE, L. and VERSCHOOR, J.A. (1993) Plasmid-encoded NAD independence in some South African isolates of Haemophilus paragallinarum. Onderstepoort Journal of Veterinary Research 60: 147-152

CLARK, D.S. and GODFREY, J.F. (1961) Studies of an inactivated Hemophilus gallinarum vaccine for immunization of chickens against infectious coryza. Avian Diseases 5: 37-47

COETZEE, L., STRYDOM, G.S. and ROGERS, E.J. (1982) The value of oil-adjuvant vaccines in the control of Haemophilus paragallinarum infection (infectious coryza) in egg producing birds in South Africa. Developments in Biological Standardisation 51: 169-180

DAVIS, R.B., RIMLER, R.B. and SHOTTS JR, R.B. (1976) Efficacy studies on Haemophilus gallinarum bacterin preparations. American Journal of Veterinary Research 37: 219-222

HORNER, R.F., BISHOP, G.C. and HAW, C. (1992) An upper respiratory disease of commercial chickens resembling infectious coryza, but caused by a V-factor independent bacterium. Avian Pathology 21: 421-427

IRITANI, Y., KATAGIRI, K. and ARITA, H. (1980) Purification and properties of Haemophilus paragallinarum hemagglutinin. American Journal of Veterinary Research 41: 2114-2118

IRITANI, Y., IWAKI, S. and YAMAGUCHI, T. (1981) Biological activity of crude polysaccharide extracted from two different immunotype strains of Hemophilus gallinarum in chickens. Avian Diseases 25: 29-37

IRITANI, Y., KUNIHIRO, K., YAMAGUCHI, T., TOMII, T. and HAYASHI, Y. (1984) Difference of immune efficacy of infectious coryza vaccine by different site of injection in chickens. Journal of the Japanese Society for Poultry Diseases 20: 182-185

JACOBS, A.A.C., CUENEN, W. and STORM, P.K. (1992) Efficacy of a trivalent Haemophilus paragallinarum vaccine compared to bivalent vaccines. Veterinary Microbiology 32: 43-49 


\section{Vaccines against infectious coryza: P.J. Blackall}

JENSEN, K.E. (1986) Synthetic adjuvants: avridine and other interferon inducers. In: Advances in Carriers and Adjuvants for Veterinary Biologics (Eds Nervig, R.M., Gough, P.M., Kaeberle, M.L. and Whetstone, C.A.), Iowa State University Press, Ames, Iowa, pp. 79-90

KONNO, Y. and NAKASE, Y. (1977) Purification of endotoxin of Haemophilus gallinarum and their biological activity. Japanese Journal of Bacteriology 32: 212

KUME, K., SAWATA, A. and NAKASE, Y. (1980a) Haemophilus infections in chickens. 3. Immunogenicity of serotypes 1 and 2 strains of Haemophilus paragallinarum. Japanese Journal of Veterinary Science 42: 673-680

KUME, K., SAWATA, A. and NAKASE, Y. (1980b) Immunological relationship between Page's and Sawata's serotype strains of Haemophilus paragallinarum. American Journal of Veterinary Research 41: $757-760$

KUME, K., SAWATA, A. and NAKASE, Y. (1980c) Relationship between protective activity and antigen structure of Haemophilus paragallinarum serotypes 1 and 2. American Journal of Veterinary Research 41: 97-100

KUME, K., SAWATA, A., NAKAI, T. and MATSUMOTO, M. (1983) Serological classification of Haemophilus paragallinarum with a hemagglutinin system. Journal of Clinical Microbiology 17: 958-964

MATSUMOTO, M. and YAMAMOTO, R. (1971) A broth bacterin against infectious coryza: immunogenicity of various preparations. Avian Diseases 15: 109-117

MATSUMOTO, M. and YAMAMOTO, R. (1975) Protective quality of an aluminum hydroxideabsorbed broth bacterin against infectious coryza. American Journal of Veterinary Research 36 $579-582$

MOUAHID, M., BISGAARD, M., MORLEY, A.J., MUTTERS, R. and MANNHEIM, W. (1992) Occurrence of V-factor (NAD) independent strains of Haemophilus paragallinarum. Veterinary Microbiology 31: 363-368

PAGE, L.A. (1962) Haemophitus infections in chickens. 1. Characteristics of 12 Haemophilus isolates recovered from diseased chickens. American Journal of Veterinary Research 23: 85-95

PAGE, L.A., ROSENWALD, A.S. and PRICE, F.C. (1963) Haemophilus infections in chickens. IV Results of laboratory and field trials of formalinized bacterins for the prevention of disease caused by Haemophilus gallinarum. Avian Diseases 7: 239-256

REID, G.G. and BLACKALL, P.J. (1987) Comparison of adjuvants for an inactivated infectious coryza vaccine. Avian Diseases 31: 59-63

RIMLER, R.B. and DAVIS, R.B. (1977) Infectious coryza: In vivo growth of Haemophilus gallinarum as a determinant for cross protection. American Journal of Veterinary Research 38: 1591-1593

RIMLER, R.B., SHOTTS JR, E.B. and DAVIS, R.B. (1975) A growth medium for the production of a bacterin for immunization against infectious coryza. Avian Diseases 19: 318-322

RIMLER, R.B., DAVIS, R.B. and PAGE, R.K. (1977) Infectious coryza: cross-protection studies, using seven strains of Haemophilus gallinarum. American Journal of Veterinary Research 38: 1587-1589

SATO, S. and SHIFRINE, M. (1964) Serologic response of chickens to experimental infection with Hemophilus gallinarum, and their immunity to challenge. Poultry Science 43: 1199-1204

SAWATA, A., KUME, K. and NAKASE, Y. (1979) Antigenic structure and relationship between serotypès 1 and 2 of Haemophilus paragallinarum. American Journal of Veterinary Research 40: 1450-1453

SAWATA, A., KUME, K. and NAKASE, Y. (1980) Biologic and serologic relationships between Page's and Sawata's serotypes of Haemophilus paragallinarum. American Journal of Veterinary Research 41: 1901-1904

TAKAGI, M., HIRAYAMA, N., MAKIE, H. and OHTA, S. (1991) Production, characterization and protective effect of monoclonal antibodies to Haemophilus paragallinarum serotype A. Veterinary Microbiology 27: 327-338

TERZOLO, H.R., PAOLICCHI, F.A., SANDOVAL, V.E., BLACKALL, P.J., YAMAGUCHI, T. and IRITANI, Y. (1993) Characterization of isolates of Haemophilus paragallinarum from Argentina. Avian Diseases 37: 310-314

WICHMANN, R.W. and WICHMANN, A.C. (1983) The cultivation of Haemophilus gallinarum in tissue culture and the use of these cultures in the preparation of a bacterin for the prevention of infectious coryza. Western Poultry Disease Conference 32: 7-10

YAMAGUCHI, T., BLACKALL, P.J., TAKIGAMI, S., IRITANI, Y. and HAYASHI, Y. (1990) Pathogenicity and serovar-specific hemagglutinating antigens of Haemophilus paragallinartim serovar B strains. Avian Diseases 34: 964-968

YAMAGUCHI, T., BLACKALL, P.J., TAKIGAMI, S., IRITANI, Y. and HAYASHI, Y. (1991) Immunogenicity of Haemophilus paragallinarum serovar B strains. Avian Diseases 35: 965-968

YAMAMOTO, R. (1991) Infectious coryza. In: Diseases of Poultry (Eds Calnek, B.W., Barnes, H.J., Beard, C.W., Reid, W.M. and Yoder Jr, H.W.), Iowa State University Press, lowa, pp. 186-195 